\title{
Rational-Emotive and Cognitive-Behavioral Interventions for Children with Anxiety Disorders: A Group Counseling Curriculum
}

\author{
Jerry Wilde \\ Indiana University East, \\ USA
}

\section{Introduction}

The purpose of this chapter is to provide overview of specific clinical interventions that can be used by rational-emotive and cognitive-behavioral therapists working with children and adolescents who are experiencing difficulties with anxiety. It is worth noting that anxiety disorders are among the most commonly occurring mental and emotional problems in childhood and adolescence. While a majority of publications focus on empirical research, there is still a need for articles that address clinical practices. REBT/CBT is, first and foremost, a system devoted to the practice of psychotherapy. Whether it is through articles focused on empirical research or clinical applications, the advancement of REBT/CBT is the ultimate goal. An anxiety management curriculum for group counseling with children is presented. While there is considerable research on the effectiveness of REBT/CBT on the treatment of anxiety, there is significantly less when it comes to the application of these principles in a group setting. The research that is available has generally found positive results for anxiety management conducted in a group counseling setting. Nine discrete lessons are offered in this chapter. The lessons presented start by setting the stage for treatment by helping clients understand that they have the ability to change their thoughts which will lead to a change in their feelings. The connection between thoughts and feelings, which is indispensable in REBT/CBT, is the focus at the beginning of group. Helping clients understand what kinds of thoughts contribute to anxious feelings is also an important component of the process. Several lessons focus on practicing ways of minimizing or managing anxious feelings by using distraction, thought stopping, and rational emotive imagery. A lesson on systematic desensitization, modified for application with children, is also offered.

\section{Rational-emotive and cognitive-behavioral interventions for children with anxiety disorders: A group counseling curriculum}

Anxiety disorders are among the most common mental and emotional problems to occur during childhood and adolescence. According to the U.S. Department of Health and Human Services (1999), 13\% of children and adolescents ages 9 to 17 experienced some type of anxiety disorder. In community samples of adult populations, the range of anxiety disorders was between 5 - 20\% with a majority of the estimates lying above 10\% (Costello \& Angold, 
1995). Blanchard, et al., (2006) found that 36\% of parents report concerns about the possibility of their children struggling with anxiety.

If left untreated, anxiety disorders can persist into adulthood (Keller, et al., 1992, Pfeffer et al., 1988; Spence, 1988) which may in part explain why the lifetime prevalence rate for anxiety disorders is $28.8 \%$, with a 12 -month prevalence of $18.8 \%$ (Kessler, \& Merikangas, 2004). The same study reported the most common subtypes of anxiety disorders to be specific phobia $(12.5 \%)$, social anxiety disorder $(12.1 \%)$, and post-traumatic stress disorder $(6.8 \%)$.

Rational Emotive Behavior Therapy (REBT) is based on the theory that emotional disturbance is largely the result of illogical and irrational patterns of thinking (Ellis, 1962, 1994). Such ideas date back to the first century A.D. when the Stoic philosopher, Epictetus (1890) wrote, "Men are disturbed not by things but by the views they take of them." In other words, it is not external events alone that cause emotional disturbance, but those events plus a person's perceptions and evaluations about them, as a good many ancient and modern philosphers have stated.

\section{The philosophical underpinnings of REBT/CBT}

Humans have a powerful predisposition or innate tendency to behave irrationally and selfdefeatingly (Ellis, 1979). They have the tendency to avoid thinking things through, to procrastinate, to be overly suggestible, superstitious, and perfectionistic. But they, at the same time, are healthy constructivists, with powerful innate tendencies to solve practical problems of living, to be creative, and to grow and develop.

REBT/CBT theory states that humans also have a strong tendency to be influenced by their environment. This is particularly true during childhood, when their family, peers, and culture have an enormous impact on their beliefs, emotions, and actions.

One of the primary tenets of REBT/CBT is that thoughts, feelings, and behaviors interact and significantly affect each other. Thinking affects, and in some ways creates, an individual's feelings and behaviors; their emotions have a very important effect on their thoughts and actions; and their actions distinctly influence their thoughts and feelings. If one of these processes are somehow altered the others are influenced as well (Ellis, 1962, 1994, 1999, 2000a, 2000b; Ellis \& Dryden, 1997; Ellis \& MacLaren, 1998).

REBT acknowledges that virtually all humans are basically hedonistic since people are born with a strong tendency to avoid pain, remain alive, and seek happiness. However, it distinguishes between long and short term hedonism in that it does not promote immediate and easy gratification at the expense of future gains.

A cardinal tenet of REBT/CBT is that all humans are fallible and have very many limitations. REBT/CBT encourages people to accept themselves as people that will now and probably forever make continual and numerous mistakes. It is important that they acknowledge their fallibility and still live happily by learning to accept themselves fully despite their limitations.

\section{Goals of rational emotive and cognitive behavior therapy}

1. To make clients more aware of their self-talk and internal dialogue and particularly of their self-defeating Beliefs, so that they will be able to think more rationally, clearly, logically and self-helpingly. 
2. To teach clients to evaluate their thinking, feeling and behavior in order to experience more healthy emotions and fewer dysfunctions.

3. To teach clients the skills to use rational emotive behavioral principles so he or she will act more functionally and be better able to achieve his or her goals in life (Wilde, 1992).

Studies have compared CBT to other forms of treatment and found it to be an effective treatment for adults suffering from various anxiety disorders. Butler et al (1991) compared CBT to behavioral therapy (BT) with results showing a clear advantage for CBT over BT. Borkovec and Costello (1993) examined the efficacy of Nondirective (ND), applied relaxation (AR), and cognitive behavioral (CBT) therapies for generalized anxiety disorder (GAD). Results for AR and CBT were generally equivalent in outcome but superior to ND at post-assessment. A preliminary meta-analysis comparing CBT to pharmacological treatment found both offered efficacy to patients. The authors reported that CBT was associated with significantly greater effects on anxiety severity and was associated with clear maintenance of treatment gains (Gould, et al, 1997).

REBT/CBT has an extensive history of being successfully applied to anxiety problems in children (Brody, 1974; Cangelosi, Gressard, \& Mines, 1980; Cristea, Benga, \& Opre,2006; DiGiuseppe \& Kassinove, 1976; Knaus \& Bokor, 1975; Knaus \& McKeever, 1977; Meyer, 1981; Micco, et al, 2007; Miller \& Kassinove, 1978; Omizo, Lo, \& Williams, 1986; Von Pohl, 1982; Warren, Deffenbacher \& Brading, 1976; Wilde, 1994, 1995, 1996a). The utility of CBT with anxiety disorders has led mental health officials in the United Kingdom to identify CBT as the first-line approach to treating anxiety disorders (National Institute for Clinical Excellence, 2004).

Rational-emotive and cognitive-behavior interventions have also been found to be beneficial in a host of other commonly occurring childhood problems such as low frustration tolerance (Brody, 1974); impulsivity (Meichenbaum \& Goodman, 1971); poor academic performance (Block, 1978; Cangelosi, Gressard, \& Mines, 1980), and depression (Wilde, 1994). Research also suggests that CBT is effective in the prevention of depression (Clarke, et al., 2001, Gilliam, et al., 1995) and in the improvement of self-concept and coping capabilities (DeVoge, 1974; DiGiuseppe, 1975; DiGiuseppe \& Kassinove, 1976; Katz, 1974; Maultsby, Knipping \& Carpenter, 1974; Omizo, Lo \& Williams, 1986; Wasserman \& Vogrin, 1979). Finally, several studies have established cognitive-behavioral interventions to be effective in increasing rational thinking in children and adolescents (DiGiuseppe \& Kassinove, 1976; Harris, 1976; Knaus \& Bokor, 1975; Miller \& Kassinove, 1978; Ritchie, 1978; Voelm, 1983; Wasserman \& Vogrin, 1979; Wilde, 1997a).

\section{An anxiety management curriculum for group counseling with children}

While there is an abundance of research on the effectiveness of REBT/CBT on the treatment of anxiety, there is significantly less when it comes to the application of these principles in a group setting. The research that is available has generally found positive results for anxiety management conducted in a group counseling setting. Liber et al., (2008) determined that group counseling is an effective means of helping children and adolescents manage feelings of anxiety. There were no outcome differences for anxious children between individual and group treatments. Liber et al. (2004) compared an individual versus a group format in the delivery of a cognitive-behavioral therapy curriculum (FRIENDS) for children with anxiety disorders. Clinically referred children (aged 8 to 12) diagnosed with Separation Anxiety Disorder $(n=52)$, Generalized Anxiety Disorder $(n=37)$, Social Phobia $(n=22)$ or Specific 
Phobia $(n=16)$ were randomly assigned to individual $(n=65)$ or group $(n=62)$ treatment. Forty-eight percent of the children in the individual versus $41 \%$ in the group treatment were free of any anxiety disorder at post-treatment and $62 \%$ versus $54 \%$ were free of their primary anxiety disorder. Regression analyses showed no significant difference in outcome between individual and group treatment.

Maes and Heimann (1970) examined the relative effectiveness of client-centered, rationalemotive, and desensitization therapies in reducing test anxiety among high school students. Thirty-three subjects with high State anxiety but average or low Trait anxiety were selected. Each student was counseled from seven to eleven times during a five-week period by advanced graduate students. There were no significant differences between the four groups in the Spielberger State-Trait Anxiety Inventory (STAI); but significant differences at $<.05$ level were found in the predicted direction between group treatments and controls on criteria of galvanic skin response (GSR) and heart rate (HR). Post hoc analyses disclosed significance for the desensitization treatment group on GSR, and the rational-emotive treatment group on HR. Final analysis revealed differences only with the rational-emotive treatment group and controls on HR.

Wessel and Mersch (1994) examined the effectiveness of REBT and exposure in vivo on testanxious adolescents. The treatment was more effective than a control waiting-list period in reducing test and social anxiety, the degree of anxiety experienced in individual anxietyprovoking situations, and the degree of avoidance of these situations.

\section{The group counseling lessons}

\subsection{Lesson 1: Setting the stage}

What follows are descriptions of a series of lessons to be used in a group setting with children experiencing difficulties with anxiety. These lessons were designed to be used in small groups of 6-10 clients but the ideas can easily be adapted for individual sessions.

Initially it is important to set the stage by helping clients accept that improvement is only possible if they take ownership over their progress. What follows is an excerpt from the book Hot Stuff to Help Kids Worry Less.

We're ready to get started except for one thing...the hard part. Are you ready to hear about the hard part? You had to know there had to be a catch, didn't you? There's always a catch. Okay, here it is.

Since there really isn't any magic in the world, you won't feel differently if you don't think and act differently. Your friends, parents, teachers, dogs, cats, and gerbils can't make you feel better. We certainly can't magically fix your life with a book, but we can help you learn some ideas and activities that have been proven to work. To feel better you're going to have to actually do some of the things that will be suggested in this book. Your life won't suddenly be perfect, but you'll have the opportunity to learn some skills that will put you in charge of your feelings.

Over the years, I have worked with hundreds of students and they've had a lot of luck with the ideas I'm going to teach you. You can learn to have a happier life, but it will not be easy. If you work hard at the things in this book, you'll probably feel better. If you don't work hard, you probably won't feel any differently. The choice is totally up to you. But keep in mind, you are also free to experience all the worries and unhappiness your heart can bear.

Learning to control your anxieties is like learning any new skill. It takes a lot of hard work and practice. There are absolutely no shortcuts, but the rewards are worth the effort. (Wilde, 2008, p. 1415). 
Sometime during the first session some type of anxiety instrument should be administered as a means of assessing the severity of the symptoms. A simple screening tool can also be introduced as a pre- and post-test to determine improvement. Below is a short screening instrument that can be used as such. It is not statistically validated and should only be used as a pre- and post-test measure.

\subsubsection{The anxiety survey}

$\begin{array}{ll}\text { Strongly } & \text { Strongly } \\ \text { Disagree } & \text { Agree }\end{array}$

1. If something bad might happen, I have to worry about it.

$\begin{array}{llllll}1 & 2 & 3 & 4 & 5 & 6\end{array}$

2. I have no control over my worrying.
1
234
5
6

3. Worrying about something can keep it from happening.
2
34

1

4. If what I worry about did happen, it would be the worst thing in the world.
$\begin{array}{llllll}1 & 2 & 3 & 4 & 5 & 6\end{array}$

5. My worries have a "mind of their own" and can't be managed.

$\begin{array}{llllll}1 & 2 & 3 & 4 & 5 & 6\end{array}$

6. If what I worry about did happen, I couldn't stand it.
12
234
$4 \quad 5$
6

7. Because I worry about things, it proves I'm worthless and weak.
$\begin{array}{llllll}1 & 2 & 3 & 4 & 5 & 6\end{array}$

8. Worries never seem to go away. Once you've got them, you're stuck with them.

$\begin{array}{llllll}1 & 2 & 3 & 4 & 5 & 6\end{array}$

TOTAL

\subsection{Lesson 2: Thoughts and feelings}

From an REBT model, it is vitally important that clients understand the connection between thoughts and feelings. The next activity is designed to help clients learn that thoughts influence, and largely control, feelings.

What follows is the story if "the blind student in the hall." It is a commonly used story in REBT circles designed to illustrate the connection between thoughts and feelings.

Let's pretend you were walking down the hall at school and somebody came up behind you and knocked all your books out of your hands. How would you feel? You'd start whistling a happy tune, right? No, seriously, how would you feel? If you're like most people, you'd probably be angry or anxious or maybe both.

But when you turned around to see who hit your books, you realized it was a blind student who accidentally bumped into you. He couldn't see where he was going and he bumped into you. Now how would you feel? Would you still feel angry and/or anxious? Probably not.

Here's the important part. You still got your books knocked out of your hands so this event (having your books scattered) can't make you feel anything. People would have different reactions to having their books knocked around. Some would feel angry, some would get anxious, and others would laugh it off along with everyone else. If events caused feelings, then everyone would feel the same way after the same events. But people don't feel the same way about things. People tend to feel differently about events so the experiences don't cause emotions. It must be something else. 
That "something else" is your thoughts. Your thoughts, beliefs, and ideas determine your feelings...not the events. (Wilde, 2008, p. 31-32.)

The second part of the lesson is designed to provide clients with additional practice making the connection between thoughts and feelings.

Below is a list of thoughts. Your job is to match the feeling that would go with each thought. You'll probably be able to do this pretty easily. Why? Because thoughts influence feelings. If they didn't, your answers would be totally different from your friends but I'll bet they'll be mostly the same. Give this a try and see how it goes.

\subsubsection{Thoughts and feelings}

What type of feeling would you have if you thought:

"Oh, no...I didn't know there was a test today."

Feeling

"What do you mean I'm grounded?"

Feeling

"I'm worthless. Everyone hates me."

Feeling

"Life stinks."

Feeling

"I hope my parents won't forget to pick me up after basketball practice."

Feeling

"It's snowing hard right now. We might have a day off of school tomorrow."

Feeling

"My mom and dad are having an argument."

Feeling

(Wilde, 2008, p. 36-37).

\subsection{Lesson 3: Focus on anxiety}

At this point it is time to start the examination of a client's anxieties. The following activity provides information about specific anxiety provoking situations as well as the intensity of the feelings related to that event or situation.

Below is a list of things that some kids worry about. Next to each item, check either "yes, I worry about it" or "no, I don't worry about it." If you checked yes, there's another column where you can record your rating from 1 to 100. This rating is called a SUDs scale, which stands for "Subjective Units of Discomfort." Scores closer to 1 mean you have less worries and scores nearer to 100 mean you have more worries. Your lowest score should be the item you

have the least worries about and your highest score would be the event that you worry about the most.

\subsubsection{My worry list}

Ghosts/Monsters

Thunderstorms

Spiders or other bugs

Being away from

my parents

Doctors/Dentists

Being made fun of

$$
\text { Yes No SUDs Score }
$$

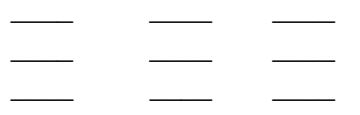


Feeling left out by

my friends

Getting hurt

A terrorist attack

Something happening

to my parents

Tests at school

Doing poorly at school

Shots/Injections

Snakes

Feeling Pain

Fires

Burglars/robbers

Getting in trouble

The dark

Elevators

Escalators

Choking

(Wilde, 2008, p. 39-40).

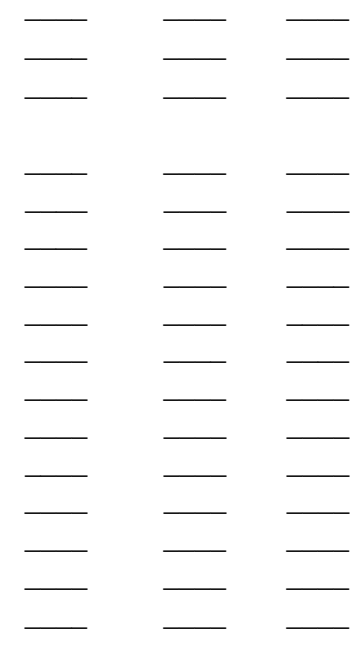

\subsection{Lesson 4: Where do worries come from?}

This lesson is designed to help students understand how situations turn from a concern to an anxiety.

As we explained a little bit earlier, worries (and all other feelings) come from thoughts. But worries don't come from just any thought. If you had the thought, "I love ice cream," you wouldn't feel anxious. Worries come from certain types of thoughts that are usually related to the possibility of something bad happening. Look over your "My Worries" list. Each item on the list could lead to something bad happening. For example, some kids are afraid of dogs because dogs could bite them. Others are afraid of being away from their parents because they're worried something might happen to their moms and dads. So most worries have at least one thing in common. There is the potential for something bad happening.

But think about this, is there any event that doesn't at least have the possibility of something bad happening? Wouldn't it be possible to win the lottery and then get a really bad paper cut from the check? Couldn't you get the bike you've always wanted and then wipe out? If your parents would let you eat all the ice cream in the world, you could get a severe case of "brain freeze."

So where do worries really come from? They come from exaggerating the "badness" of the bad outcome. I know that's not the correct way to say it but it seems to make sense to the kids I've worked with over the years. It's making the badness even badder! It's taking a bad event making it ten times worse by letting your imagination run away with you.

Now it's time to apply this idea to your worries. If you have a \# 1 worry, write it down here. Think of a \# 1 worry as the thing that you worry the most about.

My \# 1 worry is:

Okay, time for the same drill. What are three things worse than your \# 1 worry?

1.

2.

3. 
The point of this exercise is to try to help you gain some perspective. Sometimes we get ourselves so worked up worrying about the possibility of a bad event that worrying about it is worse than when it actually happens! (Wilde, 2008, p. 42-43).

It is also important to acknowledge that some clients have anxieties related to events that, if they did transpire, would have a profound impact on their lives. The treatment of these anxieties must be addressed differently. Previously the goal was to help clients gain some perspective on the negative consequences of the event (it it were to occur). When the anxiety provoking event actually has the potential to be life-threatening, it is better to focus on the statistical improbability of the event actually occurring.

But for some of you, your \# 1 worry is something that would change your life forever like something bad happening to a parent or maybe a terrorist attack or a natural disaster. You probably won't be able to list three things worse than your \# 1 (but try anyway). If this is you, your worries are coming from an entirely different place. Your worries are coming from exaggerating the possibility of the bad event really happening.

Let's say your worries are related to another terrorist attack like the one that took place on 9/11. While a terrorist attack is always possible, the odds of you personally being harmed are incredibly slim. That's because your brain gets stuck on a certain worries and completely ignores other potential dangers. For example, I'll bet you didn't know that there have been more than 50 people killed by falling vending machines since 1978. Yet, I've never met a single person who constantly worries about being crushed to death by a pop machine.

That's sort of like people who are afraid to fly on planes. They know that they are much safer traveling by plane than by car but they are still worried. And you know why? Knowing something in your brain is much different than feeling it in your "gut." When your brain and your "gut" get into a disagreement, your "gut" usually wins. At least for a few rounds until the brains gets better prepared (Wilde, 2008, p. 44-45).

\subsection{Lesson 5: Distraction}

The cardinal tenet of REBT is that emotions are not caused directly by events but are primarily the result of the thoughts and beliefs an individual has about the event. Therefore, if children are able to modify their thoughts about an event, they will change their feelings as well. One of the simplest and most effective techniques designed to bring about a change in thinking involves the use of a distraction technique (Wilde, 1997b; Wilde 1996b; Wilde 1995).

Distraction is not an "elegant solution" as Ellis would say. It does not involve a change in assessment of the event and, therefore, it would not be considered to be bringing about cognitive restructuring. Distraction, as the name implies, merely attempts to help children think of something other than their current situation. This is more difficult than it sounds because when children are getting anxious, the only thing they seem to be able to think about is the situation at hand. That is why clients need to decide what to think about before they start becoming anxious.

Encourage clients to pick "a scene" to use before they encounter the event they become anxious about. This memory should be either the happiest, funniest, or most relaxing scene they can remember. For example:

- A memorable day at the beach or on vacation

- The time they won a game

- A hysterically funny event from their past

- A memorable birthday party 
Have clients take a few minutes and think about the distraction scene. You may need to help clients select the scene that fits their individual needs. Now they need to practice imagining this scene several times daily for the next few days or weeks. When clients have some free time have them close their eyes and picture their distraction scene. Clients should be advised to bring in all the details that they can possibly remember to make the scene vivid.

What were the people wearing?

What were the sounds they can remember?

Were there any smells in the air?

Encourage clients to create scenes in their minds just like watching a videotape of the event. It can also be helpful to have them draw their distraction scene and then explain it to the therapist.

The idea is to switch to this distraction scene when the clients find themselves getting anxious. Instead of focusing on the situation they are getting anxious about, they are to concentrate on their distraction scene. Instead of getting anxious before an important examination in school, they are to concentrate on the distraction scene until the feelings start to subside. Whenever they feel themselves getting anxious, they are to switch to their scene. It is impossible for clients to think of a distraction scene and still become anxious. Since anxiety is produced by beliefs, thinking about a funny or happy memory will keep them from getting upset or minimize the intensity of the emotions.

\subsection{Lesson 6: Rational emotive imagery}

What follows is an example of how the imagination game or rational-emotive imagery (REI) can be used with children and adolescents who have anxiety problems. Ellis $(1994 ; 1979)$ and Wilde (1995; 1996a; 1997b) have used REI extensively in the treatment of anxiety and anger problems. This technique is most effective if there is a particular situation (i.e., certain social situations, public speaking, separation from parents) in which anxiety is likely to occur.

Start by having the child vividly describe the troublesome scenario. Get as many details as possible about the sights, sounds, and events in this situation. Then have the child get as relaxed as possible in his or her chair with both feet on the floor. Spend several minutes describing relaxing images until you can see the behavioral manifestations of relaxations starting to appear. The use progressive relaxation techniques with the successive contracting and relaxing of various muscle groups can be very helpful. After the client appears to be sufficiently relaxed, start with the following dialogue.

Therapist: Anna, I want you to listen very closely to what I'm going to tell you. I want you to be aware only of my voice and focus on what I say. Try to block everything else out of your mind for the time being.

Imagine you are back in your classroom and students are taking turns reading aloud. Picture the room in your mind. See all the posters on the walls and everything else that is in your class. Now go ahead and let yourself feel like you do when it's reading time. Feel all the anxiety you felt back then. Stay with that scene and try to feel just like you felt in the class. When you feel that way, wiggle your finger and let me know you're there.

(Author's note - It's a good idea to look for behavioral signs confirming that the child is actually feeling anxious. The jaw may tighten, eyebrows furrow and many children will shift or squirm in their seats.)

Stay with that feeling. Keep imagining that you are in your classroom. 
(Author's note - Allow the child to stay in this state for approximately 20 to 40 seconds. Remind him or her to mentally stay in the situation.)

Now I want you to keep thinking you are in the class but I want you to calm yourself down. Stay in the classroom in your mind but try to calm down. Instead of being very upset, try to get calmer. Instead of being really anxious, try to work toward feeling calmer. Keep working at it until you can calm yourself down. When you can make yourself calm, wiggle your finger again.

Usually students can reach a state of relative calm within a fairly short period of time. Once a child has wiggled his or her finger, it is time to bring him or her back to the here and now. Simply say something like, "Okay, now open your eyes." Next ask, "What did you say to yourself to calm yourself down?" If the child was able to calm down, he or she had to be thinking some type of rational coping statement. The only other way to calm down would be to mentally leave the situation (i.e., no longer visualize the classroom). This usually doesn't happen but if it does, try the exercise over encouraging the child to keep imagining the scene but working to calm down.

After completing the imagination game students should then be able to state the thought that allowed them to calm down. A typical calming thought that might have been produced from the above scenario would be, "Even though I don't read well, it's not that big of a deal. It doesn't mean I'm a bad person. Other students have problems reading aloud."

Once the child has produced a rational coping statement, write it down. Now he or she can practice this mental imagery several times a day and use this same calming thought each time. In effect, this technique allows kids to mentally practice dealing with a difficult situation in a new, more productive way. It's very important that they practice REI on a regular basis if they are going to learn to handle their anxiety in a more productive fashion. Usually children can learn to do the Imagination Game by themselves after having been led through the technique a few times by the therapist. It is also possible to make a tape recording of this intervention for the child to use at home as some students like using the tape rather than leading themselves through this technique. Both can be effective if used regularly.

\subsection{Lesson 7: Thought stopping}

Ever since Joseph Wolpe (1958) first published descriptions of thought-stopping techniques, clinicians have been applying these types of interventions. There has been a plethora of case studies published over the years claiming reductions in anxiety symptoms with both adults and children. However, the results of experimental investigations have been inconsistent. Several of these studies have suffered from methodological shortcomings such as the lack of a control group or no follow-up analysis to determine if results have been maintained.

The general framework for teaching clients to use thought-stopping techniques follows a progression that begins with the therapist being more overtly involved and gradually diminishing involvement until the client is able to use the intervention independently. This interventions starts by having clients imagine the anxiety-provoking situation and vocalizing their thoughts. When clients first utter an irrational anxiety-producing thought such as, "If I did a bad job of reading in front of the class, I'd die," the therapist shouts, "Stop." Practice this first step until clients report that the therapist shouting, "Stop" interrupted their irrational thinking. The second step involves having clients merely think of the anxiety-provoking situation and signal the therapist whenever they were thinking an irrational thought. Upon observing the signal, the therapist again shouts, "Stop." 
The problem with most thought stopping interventions is that they stop at this point. Clients can learn how to stop a disturbing thought but unless they can replace the anxietyproducing thought with a rational cognition, the original thought will quickly return. The next important step involves having clients think about positive, rational and/or calming thoughts that could substitute for the anxiety producing thought. Clients are taught to imagine the anxiety-provoking situation and when they began to think irrational thought they are to say their rational coping statement aloud. Once again, practice this until clients report that they are able to consistently reduce their anxiety to a manageable level. The use of a self-report scale (such as the subjective units of discomfort scale) with a range from 1-10 can be helpful to quantify the intensity of their emotions. The final step involves having clients practice transferring the rational coping statement from an overt statement to internal dialogue. Now they are to merely think their rational coping statement whenever they notice they are beginning to feel anxious.

\subsection{Lesson 8: Systematic desensitization}

This lesson teaches the clients how to use gradual exposure and relaxation as a means of learning to manage specific phobias.

One of the most common ways to get over a specific anxiety is to start by approaching the problem slowly. You know, taking small steps toward your goal until you are better able to manage the anxiety. Mental health professionals call this systematic desensitization and it is used a lot with kids and adults who have difficulties with anxiety.

If you were afraid of the water, there are a number of ways you could try to conquer your anxiety. You could get in a boat, drive out into the middle of a lake, and jump in. That would be one approach but probably not the best one. You could also start by using a pool. At first, you might need to stand on the deck of the pool and not actually go near the water. After you were able to stand on the deck without being too anxious, maybe you could slowly wade into the water. Maybe you'd have to start the wading in the baby pool. Each day you could go a couple of inches deeper and stay there until you were able to relax. With enough time and plenty of support, you'd eventually be able to go all the way into the water. That's the way systematic desensitization works and we're going to try to help you understand how to apply it to your worries.

One of the first things to do is create a "Fear Thermometer" which is kind of like the SUDs scale. You start by listing the things that you get a little anxious about (like standing on the side of the pool), and you keep going up the thermometer until you list the things you are very anxious about (jumping in the deep end of the pool). The thermometer goes from 1 to 100 so for each event you have to give it a score (or temperature).

Using the pool example, a Fear Thermometer might look like this:

\section{Event}

Jumping into deep end without life jacket

Jumping into deep end with life jacket

Wading in chest deep water

Wading in waist deep water

Wading in knee deep water

Walking into the water at a pool

Walking into the water at the baby pool

Standing on the deck of a pool
Temperature

99

90

75

65

50

40

35

20 
Looking at a pool 10

Seeing people swimming on video 5

So the plan would be to start at the bottom with video of people swimming. While watching the video, you would repeat a self-calming statement while doing rational-emotive imagery just like we practiced a few pages ago. It might be a self-calming statement like, "I am safe. Nothing bad is going to happen to me in the water" or something like that. Some people use a mental picture of a relaxing event (like clouds floating across the sky) and when they start to feel anxious, they switch to that image. Feel free to experiment to determine which one works best for you. When you can look at that video of someone swimming without feeling overwhelmed by worries, it is time to move to the next event on the Fear Thermometer. You keep using the same set of procedures until you can reach the top of the Fear Thermometer.

Now, it's time for you to make your own Fear Thermometer. I used eight lines but if you need more, feel free to take out a separate sheet of paper.

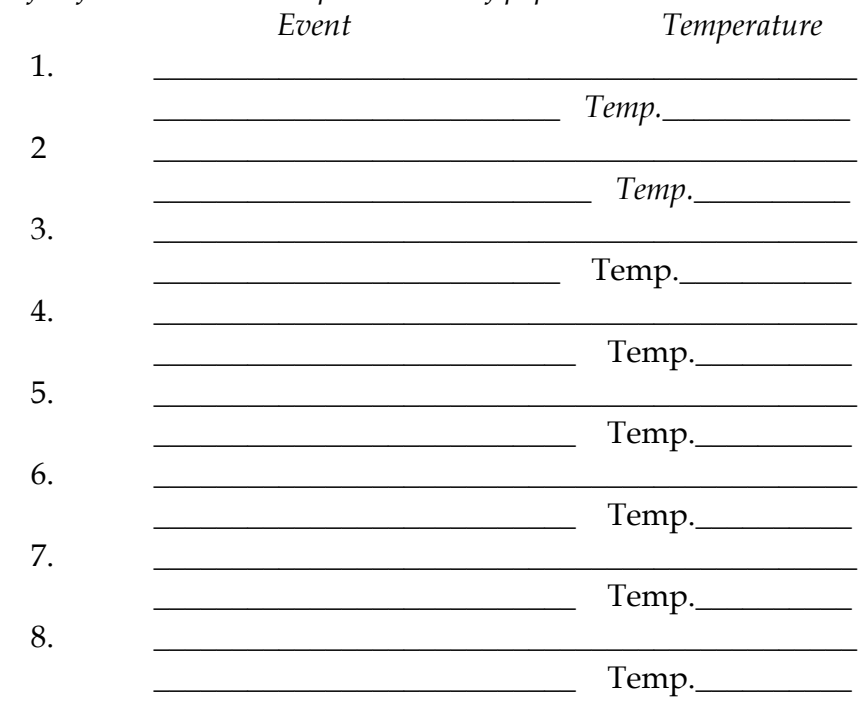

Write down your self-calming statement or calming mental image you will use to relax here.

Remember, start at the bottom and when you are able to "manage" that situation without feeling too much anxiety, move up the list. This will take time so be patient. Sometimes it will take weeks and even months to work through your list. Don't expect to master the list overnight Wilde, 2008, p. 58-62).

\subsection{Lesson 9: Worry brain vs. calm brain}

This lesson is to determine if clients have mastered the skill of understanding the difference between 1) a rational thought and 2) an irrational exaggeration. Clients are challenged to come up with both for this lesson.

I call this "Worry Brain vs. Calm Brain." It can be used with any situation you get anxious about but it's a good idea to use it with the one you've been having the most trouble with. Below are two 
sets of brains. Your job is to write a "Worry Brain" thought and a "Calm Brain" thought in the lines provided.

Let's use the example of being afraid of storms to illustrate what you are supposed to do. In this scenario, you have just seen that the sky is turning dark. The worry brain thinks, "Oh no, it might thunder and lightning and that would be terrible." The calm brain thinks, "Well, there might be a storm but that wouldn't be the worst thing in the world. I'm safe here inside." Next, the worry brain thinks, "It could turn into a tornado and come right at the house." The calm brain thinks, "It could turn into a tornado but it never has before. In fact, in the history of our town, there's never been a single house hit by a tornado. The odds are that I'll be safe." Do you see how it works? This will give your calm brain a chance to practice overpowering your worry brain. Select a situation you get anxious about and practice writing both "Worry Brain" thoughts and then countering that with a "Calm Brain" answers. Give it a shot! Feel free to take out a blank piece of paper and practice this "Worry Brain vs. Calm Brain" all you want. It's easy once you get the hang of it.

1. Worry Brain Thought

1.a. Calm Brain Thought

2. Worry Brain Thought

2.a. Calm Brain Thought

(Wilde, 2008, p. 66-67)

\section{Summary}

Anxiety problems are among the most commonly diagnosed mental and emotional problems to occur during childhood and adolescence. Research suggests that if left untreated, many children will struggle with anxiety later in life. The interventions discussed in this article are relatively brief and are designed to be used in a group counseling setting. While there is an abundance of research on the effectiveness of REBT and CBT on the treatment of anxiety, there is significantly less when it comes to the application of these principles in a group setting. The research that is available has generally found positive results for anxiety management conducted in a group counseling setting. The lessons presented in this chapter start by setting the stage by helping clients understand that they have the ability to change their thoughts and thus, change their feelings. The connection between thoughts and feeling-essential when using REBT/CBT - is stressed in the beginning of group. Helping clients understand what kinds of thoughts contribute to anxious feelings is also an important component of the process. Several lessons focus on clients practicing ways of minimizing and managing anxiety are also presented (distraction, thought stopping, rational emotive imagery). Finally, a lesson designed to allow clients to practice using systematic desensitization is offered. 


\section{References}

Blanchard L.T., Gukra, M., Blackman, J. (2004). Emotional, developmental, and behavioral health of American children and their families: A report from the 2003 National Survey of Children's Health. Pediatrics, 117, 6, 1202-12.

Block, J. (1978). Effects of rational-emotive mental health program on poorly achieving, disruptive high school students. Journal of Counseling Psychology, 25, 61-65.

Borkovec, T, and Costello, E. (1993). Efficacy of applied relaxation and cognitive-behavioral therapy in the treatment of generalized anxiety disorder. Journal of Consulting and Clinical Psychology, 61, 611-619.

Brody, M. (1974). The effects of rational-emotive affective education on anxiety, self-esteem, and frustration tolerance. Unpublished doctoral dissertation, Temple University, Philadelphia.

Butler, G. Fennell, M., Robson, P., Gelder, M. (1991). Comparison of behavior therapy and cognitive behavior therapy in the treatment of generalized anxiety disorder. Journal of Consulting and Clinical Psychology, 59, 167-175.

Cangelosi, A., Gressard, C., \& Mines, R. (1980). The effects of rational thinking groups on self-concepts in adolescents. The School Counselor, 14, 357-361.

Clarke, G. N., Hornbrook, M., Lynch, F., Polen, M., Gale, J., \& Beardslee, W., (2001). A randomized trial of a group cognitive intervention for preventing depression in adolescent offspring of depressed parents. Archives of General Psychiatry, 58, 11271134.

Costello, E.J. \& Angold, A. (1995). Epidemiology. In J.S. March (ed.), Anxiety disorders in children and adolescents. New York, Guildford.

Cristea, I. A. ; Benga, O. \& Opre, A. (2006). The comparative efficiency of a rational-emotive education intervention for anxiety in $3^{\text {rd }}$ grade children: An analysis of relevant developmental constraints. Cognitie, Creier, Comportament/Cognition, Brain, Behavior, 10, 637-657.

DeVoge, C. (1974). A behavioral approach to RET with children. Rational Living, 9, 23-26.

DiGiuseppe, R. (1975) A developmental study on the efficacy of rational-emotive education. Unpublished doctoral dissertation, Hofstra University.

DiGiuseppe, R., \& Kassinove, H. (1976). Effects of a rational-emotive school mental health program in children's emotional adjustment. Journal of Community Psychology, 4, 382-387.

Ellis, A. (1962). Reason and emotion in psychotherapy. Philadelphia: Citadel Press.

Ellis, A. (1979). The theory of rational-emotive therapy. In A. Ellis \& J. Whiteley (Eds.), Theoretical and empirical foundations of rational-emotive therapy. (p. 9 - 26). Monterey, CA: Brooks/Cole.

Ellis, A. (1994). Reason and emotion in psychotherapy: Revised edition. Philadelphia: Citadel Press.

Ellis, A. (1999). How to be happy and remarkably less disturbable. Atascadero, CA: Impact Publishers.

Ellis, A. (2001) Feeling better, getting better, staying better. Atascadero, CA: Impact Publishers.

Ellis, A. (2000b) Rational emotive self-help techniques. New York, NY: Guilford Press.

Ellis, A. \& Dryden, W. (1997). The practice of rational emotive behavior therapy. New York, NY: Springer Publishing.

Ellis, A., \& Harper, R. (1975). The new guide to rational living. Los Angeles: Wilshire. 
Ellis, A., \& Harper, R. (1997). A guide to rational living. North Hollywood: Wilshire.

Ellis, A. \& MacLaren, C. (1998). Rational emotive behavior therapy: A therapist's guide. Atascadero, CA: Impact Publishers.

Gillham, J. E., Reivich, K. J., Jaycox, L. H., \& Seligman, M. P. E. (1995). Prevention of depressive symptoms in schoolchildren: Two-year follow-up. Psychological Science, $6,343-351$.

Gould, M., Otto, M., Pollack, M., and Yap, L. (1997). Cognitive behavioral and pharmacological treatment of generalized anxiety disorder: A preliminary metaanalysis. Behavior Therapy, 28, 285-305.

Katz, S. (1974). The effect of emotional education on locus of control and self-concept. Unpublished doctoral dissertation, Hofstra University.

Keller, M. B., Lavori, P., Wunder, J., Beardslee, W. R., Schwarts, C. E., \& Roth, J. (1992). Chronic course of anxiety disorders in children and adolescents. Journal of the American Academy of Child and Adolescent Psychiatry, 31, 595-599.

Kessler, R. \& Merikangas, K. (2004). The national comorbidity survey replication (NCS-R): Background and aims. International Journal of Methods in Psychiatric Research, 13, 2, 60-68.

Knaus, W., \& Bokor, S. (1975). The effects of rational-emotive education on anxiety and selfconcept. Rational Living, 10, 7-10.

Knaus, W., \& McKeever, C. (1977). Rational-emotive education on anxiety and self-concept. Journal of Rational Living, 10, 7-10.

Liber, J., Van Widenfelt, B. Utens, E., Ferdinand, R. Van Der Leeden, A., Van Gastel, W., \& Treffers, P. (2008). No differences between group versus individual treatment of childhood anxiety disorders in a randomised clinical trial. Journal of Child Psychology and Psychiatry, 49, 886-893.

Maes, W., \& Heimann, R. (1970). The comparison of three approaches to the reduction of test anxiety in high school students. U.S. Department of Health, Education and Welfare, Washington, D.C., 1-73.

Maultsby, M., Knipping, P., \& Carpenter, L. (1974). Teaching self-help in the classroom with rational self-counseling. Journal of School Health, 44, 445-448.

Meichenbaum, D., \& Goodman, J. (1971). Training impulsive children to talk to themselves. Journal of Abnormal Psychology, 77, 115-126.

Meyer, D. (1981). Effects of rational-emotive therapy upon anxiety and self-esteem of learning disabled children. Ann Arbor, MI: University of Michigan.

Micco, J.; Choate-Summers, M.; Ehrenreich, J.; Pincus, D.\& Mattis, S. (2007). Identifying efficacious treatment components of panic control treatment for adolescents: A preliminary examination. Child \& Family Behavior Therapy, 29, 1-23.

Miller, N., \& Kassinove, H. (1978). Effects of behavioral rehearsal, written homework, and level of intelligence on the efficacy of rational-emotive education in elementary school children. Journal of Community Psychology, 6, 366-373.

National Institute for Clinical Excellence (2004). Anxiety: Management of anxiety (panic disorder, with or without agoraphobia, and generalized anxiety disorder) in adults in primary, secondary and community care. Retrieved October 7, 2007 from www.nice.org.uk/CG022quickrefguide. 
Omizo, M., Lo, F., \& William, R. (1986). Rational-emotive education, self-concept, and locus of control among learning disabled students. Journal of Humanistic Education and Development, 25, 59-69.

Pfeffer, C., Lipkins, R., Plutchik, R. \& Mizruchi, M. (1988). Normal children at risk for suicidal behavior: A two-year follow-up study. Journal of the American Academy of Child and Adolescent Psychiatry, 27, 34-41.

Ritchie, B. (1978). The effects of rational-emotive education on irrational beliefs, assertiveness, and/or locus of control in fifth grade students. Unpublished doctoral dissertation, Virginia Polytechnic University.

Spence, S. (1998). A measure of anxiety symptoms among children. Behavior and Research Therapy. 36, 545-566.

U.S. Department of Health and Human Services. (1999). Mental Health: A Report of the Surgeon General. Rockville, MD: U.S. Department of Health and Human Services.

Voelm, C. (1983). The efficacy of teaching rational-emotive education to acting-out and socially withdrawn adolescents. Unpublished doctoral dissertation, California School of Professional Psychology.

Von Pohl, R. (1982). A study to assess the effects of rational-emotive therapy with a selected group of emotionally disturbed children in day and residential treatment. Unpublished doctoral dissertation, University of Alabama, Birmingham.

Wasserman T., \& Vogrin D. (1979). Relationship of endorsement of rational beliefs, age, months treatment and intelligence to overt behavior of emotionally disturbed children. Psychological Reports, 44, 911-917.

Warren, R., Deffenbacher, J., \& Brading, P. (1976). Rational-emotive therapy and the reduction of test anxiety in elementary school students. Rational Living, 11, 28-29.

Wessel, I. \& Mersch, P. (1994). A cognitive-behavioural group treatment for test-anxious adolescents. Anxiety, Stress \& Coping: An International Journal, Vol.7(2), 149-160.

Wilde, J. (1992). Rational counseling with school aged populations: A practical guide. Muncie, IN: Accelerated Development.

Wilde, J. (1994). The effects of the let's get rational board game on rational thinking, depression, and self-acceptance in adolescents. The Journal of Rational-Emotive and Cognitive-Behavior Therapy, 12, 189-196.

Wilde, J. (1995). Anger management in schools: Alternatives to student violence. Lancaster, PA: Technomic Publishing Company, Inc.

Wilde, J. (1996a). Rational-emotive behavior therapy and the treatment of phobias in children. Anxiety Disorders Practice Journal, 2 (2), 189-195.

Wilde, J. (1996b). Treating anger, anxiety, and depression in children and adolescents: A cognitivebehavioral perspective. Muncie, IN: Accelerated Development.

Wilde, J. (1997a). The efficacy of short-term rational-emotive education with fourth grade students. Elementary School Guidance and Counseling, 31, 131-138.

Wilde, J. (1997b) Hot stuff to help kids chill out: The anger management book. East Troy, WI: LGR Publishing.

Wilde, J. (2008) Hot stuff to help kids worry less: The anxiety management book. Richmond, IN: LGR Publishing.

Wolpe, J. (1958). Psychotherapy by reciprocal inhibition. Stanford University Press, Berkley, CA. 


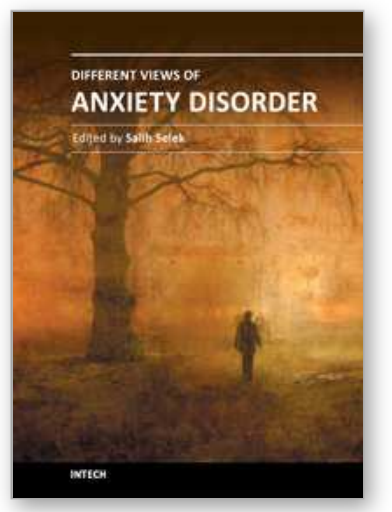

\author{
Different Views of Anxiety Disorders \\ Edited by Dr. Salih Selek
}

ISBN 978-953-307-560-0

Hard cover, 370 pages

Publisher InTech

Published online 12, September, 2011

Published in print edition September, 2011

Anxiety, whether an illness or emotion, is a term with historical roots even in the Bible, but it was not popular until the modern age. Today, we can group, diagnose and treat several anxiety disorders to an extent, but the assessment of symptoms and severity, dealing with resistant conditions, new treatment modalities and specific patient population, such as children, are still the challenging aspects of anxiety disorders. This book intends to present anxiety disorders from a different view and discuss a wide variety of topics in anxiety from a multidimensional approach. This Open Access book addresses not only psychiatrists but also a broad range of specialists, including psychologists, neuroscientists and other mental health professionals.

\title{
How to reference
}

In order to correctly reference this scholarly work, feel free to copy and paste the following:

Jerry Wilde (2011). Rational-Emotive and Cognitive-Behavioral Interventions for Children with Anxiety Disorders: A Group Counseling Curriculum, Different Views of Anxiety Disorders, Dr. Salih Selek (Ed.), ISBN: 978-953-307-560-0, InTech, Available from: http://www.intechopen.com/books/different-views-of-anxietydisorders/rational-emotive-and-cognitive-behavioral-interventions-for-children-with-anxiety-disorders-a-group-

\section{INTECH}

open science | open minds

\section{InTech Europe}

University Campus STeP Ri

Slavka Krautzeka 83/A

51000 Rijeka, Croatia

Phone: +385 (51) 770447

Fax: +385 (51) 686166

www.intechopen.com

\section{InTech China}

Unit 405, Office Block, Hotel Equatorial Shanghai

No.65, Yan An Road (West), Shanghai, 200040, China

中国上海市延安西路65号上海国际贵都大饭店办公楼405单元

Phone: +86-21-62489820

Fax: +86-21-62489821 
(C) 2011 The Author(s). Licensee IntechOpen. This chapter is distributed under the terms of the Creative Commons Attribution-NonCommercialShareAlike-3.0 License, which permits use, distribution and reproduction for non-commercial purposes, provided the original is properly cited and derivative works building on this content are distributed under the same license. 